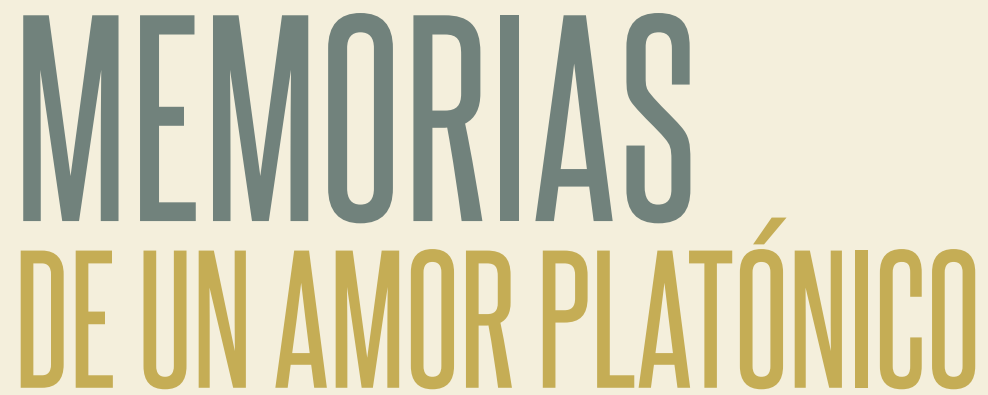

\title{
Claudia Ramírez
}

\section{Ha pasado tanto tiempo desde el último en- cuentro que tuve con mi Mamá Elena bioló- gica que las memorias ya no saben discernir entre la ficción y la fantasía; dos conceptos producto de la imaginación porque así, como una ilusión familiar, fue precisamente nuestra relación.}

\begin{abstract}
Indudablemente, tratándose de partir, desmantelar, desmembrar, desollar, destetar, desjarretar, desbarretar o desmadrar algo, Mamá Elena era una maestra.
\end{abstract}

LAURA ESQUIVEL, Como agua para chocolate

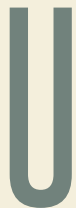

n día, después de leer Carta al padre de Kafka, decidí hablar sobre mis madres. Así en plural porque aquella cuya sangre pulula por mi cuerpo ya no me reconoce ni mucho menos sabe quién soy. De igual forma hablo sin saber sobre quién lo hago en realidad. Incluso desconozco por qué escribo lo que aquí escribiré. Quizá sea por mera necesidad, como una especie de catarsis liberadora de mi cuna trágica. Ha pasado tanto tiempo desde el último encuentro que tuve con mi Mamá Elena biológi- ca que las memorias ya no saben discernir entre la ficción y la fantasía; dos conceptos producto de la imaginación porque así, como una ilusión familiar, fue precisamente nuestra relación. Que si ocurrió esto o aquello, que si en realidad no ocurrió nada, who cares? Solo pretendo dibujar esa imagen que es fundamental para cualquier ser humano y de la que todos hablan: la de la madre. Pero bajo el velo de su ausencia, ¿cómo elegir entre las tantas madres que pasaron por mi vida, que fueron todo $y$ a la vez nada? Será mejor que acuda a todas ellas para difuminarlas en una.

De acuerdo con la RAE, la palabra madre tiene muchas acepciones. La primera corresponde a aquella mujer o hembra que ha parido a otro ser de la misma especie. Se dice que a la hora de parir, por ciertas sustancias químicas que se desprenden del organismo, como la dopamina, la madre crea un vín- culo emocional con su cría. Así mismo, la cría, debido a su vulnerabilidad, desarrolla una conducta de apego hacia la madre. Sin embargo no siempre ocurre esto. $\mathrm{O}$ la dopamina de Mamá Elena decidió no funcionar esa madrugada de invierno en que mi vulnerabilidad se abrió camino en este mundo, o simplemente no pertenecemos a la misma especie. Ella, tierra alta de un bravo volcán, sobre la cual uno tiene que caminar con precaución tanteando el terreno por si decide hacer erupción. (O como dirían en mi barrio, "con ella ponte bien trucha”.) Y yo, la más profunda agua de los océanos con la cual se vierte la fuente del misterio, de la melancolía y de la pasividad, que jamás pude ponerme trucha. Hasta el día de hoy me pregunto: ¿a quién se le habrá ocurrido mezclar estos dos elementos que son totalmente contrarios? Solo Dios sabrá. Y, en realidad, fuera de su histeria nunca llegué a conocerla, mucho menos a comprenderla. Sé que su pasado fue trágico, pero $\mathrm{mi}$ propia tragedia ya era suficiente como para andar mirando más allá de mis propias preocupaciones. $Y$ ahora, aunque su imagen me parece muy borrosa, en mi ADN aún hay algo que me cala hondo: su ausencia cada 10 de mayo. No sé si sea a causa del barullo de la mercadotecnia o del apego nuevemesino al claustro materno, pero algo se nubla en mí durante ese día. En contraparte, según un diccionario de símbolos que leí en la universidad, la madre también puede ser terrible, ya que para algunas culturas simboliza la muerte y tiene el poder, la capacidad de darle punto final a la vida al igual que la madre naturaleza. Mi Mamá Elena representa precisamente eso: mi vida y mi muerte. Así nomás.

La tercera definición de la RAE, la cual me parece un tanto ambigua, dice: "mujer que ejerce las funciones de madre". Intuyen- 
do dichas funciones, traeré a mi mente a Mamá Elena 2. La nombro así no porque se parezca a la Mamá Elena de Laura Esquivel ni mucho menos a mi Mamá Elena biológica, sino porque a causa de la brecha generacional que existía entre nosotras yo la percibía como una mujer que se había criado bajo las creencias porfirianas (claro que esto, más que a su edad, se debía a la crianza de su madre, mi bisabuela). Por supuesto que estoy hablando de mi abuela, aunque esta palabra me parece extraña, pues jamás la miré de esta manera. Mujer matriarcal y culta, de carácter fuerte pero con un elegante sentido del humor, ella fue la que me enseñó que si me llegara a faltar un pie caminara con el otro, y siempre que se avecinaba la erupción del volcán me brindaba refugio en su cama. La recuerdo sobre todo por su exquisita comida y su ingenio lingüístico: le encantaba inventarse juegos de palabras, decir proverbios y chistoretes. Si no se hubiera dedicado a la crianza de sus hijos, para lo cual no era diestra, estoy segura que hubiera sido una escritora talentosa. Además, no es que generalice pero, al igual que cualquier profesional dedicada de lleno a su trabajo, en materia de crianzas y de amor ella no ahondaba. Me reconforta pensar que de toda la familia soy yo la que se siente orgullosa de haber conquistado su frío corazón. He de admitir que de todas mis madres es la que más me pesa. Su ausencia llegó demasiado pronto a mi vida, cuando apenas se avecinaba la verdadera tormenta: mi adolescencia. La crueldad de la naturaleza, esa "madre terrible", se la llevó una noche de septiembre mientras ella callaba y nosotros ignorábamos su enfermedad. No estoy segura de si realmente no sufrió. Aunque no se quejaba, su mirada ya se había tornado triste y melancólica; su amor extrañamente se había transfor-

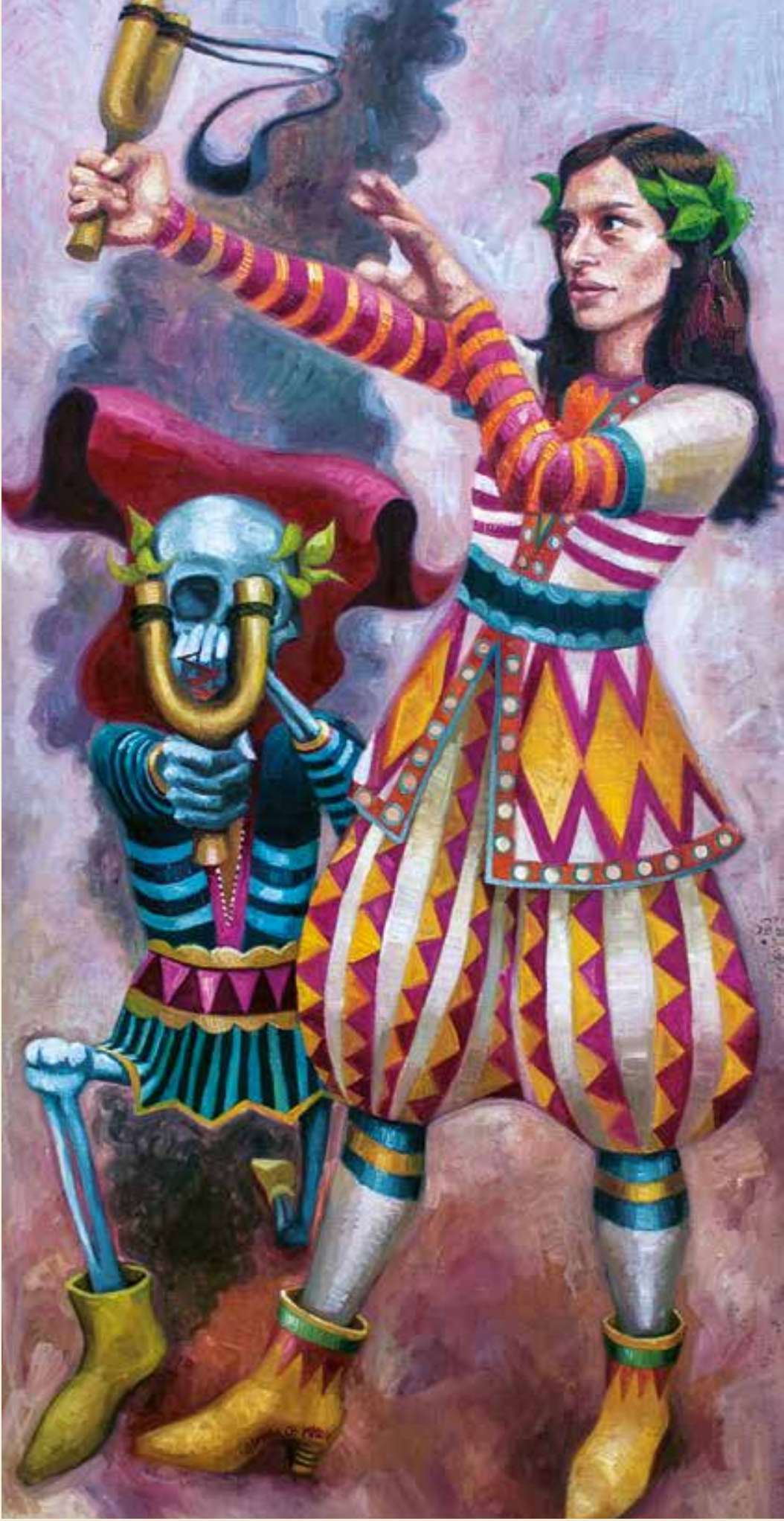

XIII. De la serie Unus Mundus.

mado en palabras. Después de un "te quiero mucho, mija", no volví a verla jamás. Sufrí mucho y mis ojos se vaciaron, llené de lágrimas todos los rincones de mi pubertad. Al final, con esta ausencia no dejó de enseñarme pues en Mi ADN hay algo que resuena gracias a ella: su fortaleza que es la mía.

Por supuesto que tuve otras madres antagónicas o secundarias, pues qué mujer en su sano juicio no sufre por aquella niña desamparada y semihuérfana. $Y$ 
